\title{
Bending Stiffness of Truss-Reinforced Steel-Concrete Composite Beams
}

\author{
Francesco Trentadue1, Erika Mastromarino², Giuseppe Quaranta ${ }^{3}$, Floriana Petrone4, \\ Giorgio Monti ${ }^{3}$, Giuseppe Carlo Marano ${ }^{{ }^{*}}$ \\ ${ }^{1}$ Department of Civil Engineering and Architecture, Technical University of Bari, Bari, Italy \\ ${ }^{2}$ Metal.Ri s.r.I - via Giuseppe Abbruzzese, 42 - 70020 Bitetto (BA) \\ ${ }^{3}$ Department of Structural and Geotechnical Engineering, Sapienza University of Rome, Rome, Italy \\ ${ }^{4}$ Department of Civil and Environmental Engineering, University of California, Davis, CA, USA \\ Email: ${ }^{*}$ giuseppecarlo.marano@poliba.it
}

Received 14 June 2014; revised 5 August 2014; accepted 16 August 2014

Copyright (C) 2014 by authors and Scientific Research Publishing Inc.

This work is licensed under the Creative Commons Attribution International License (CC BY).

http://creativecommons.org/licenses/by/4.0/

c) (i) Open Access

\begin{abstract}
This paper is concerned with a special steel-concrete composite beam in which the resisting system is a truss structure whose bottom chord is made of a steel plate supporting the precast floor system. This system works in two distinct phases with two different resisting mechanisms: during the construction phase, the truss structure bears the precast floor system and the resisting system is that of a simply supported steel truss; once the concrete has hardened, the truss structure becomes the reinforcing element of a steel-concrete composite beam, where it is also in a pre-stressed condition due to the loads carried before the hardening of concrete. Within this framework, the effects of the diagonal bars on the bending stiffness of this composite beam are investigated. First, a closed-form solution for the evaluation of the equivalent bending stiffness is derived. Subsequently, the influence of geometrical and mechanical characteristics of shear reinforcement is studied. Finally, results obtained from parametric and numerical analyses are discussed.
\end{abstract}

\section{Keywords}

Bending Stiffness, Steel-Concrete Composite Beams, Precast Floor Systems

\section{Introduction}

Steel-concrete composite structural members—such as beams, columns and slabs_-are widely used in modern

*Corresponding author.

How to cite this paper: Trentadue, F., Mastromarino, E., Quaranta, G., Petrone, F., Monti, G. and Marano, G.C. (2014) Bending Stiffness of Truss-Reinforced Steel-Concrete Composite Beams. Open Journal of Civil Engineering, 4, 285-300. 
civil engineering structures, as illustrated in Kasuga et al. [1], Stráský et al. [2] and Durfee [3]. Within this framework, the paper deals with a particular class of steel-concrete composite beams that is widely diffused in Italy to build large structures (Figure 1). This special composite beam is made up of ribbed or smooth diagonal bars primarily designed to withstand tangential stresses. At the top, these bars are welded to the upper chord, which is usually made up of symmetrically placed longitudinal bars having circular or square cross-section. At the bottom, the diagonal bars are usually welded to a thin steel plate, even though other technological solutions are available (i.e., a reinforced/prestressed concrete thick plate can be used instead). The steel plate has a constant thickness along the beam span, and additional bars can be longitudinally welded on it in order to increase the positive resisting moment. Standard welded connections are adopted to assemble the elements of this special steel truss structure in the factory. It is common practice to adopt constant cross-sections for all steel members of the truss structure (upper bars, lower plate, diagonal bars), so to ease its construction. The lower chord is usually designed in such a way that the bottom plate can provide support to the transversally-placed slabs (Figure 2) if they have the same depth of the beam. In case of deep beams, the lower chord can be a U-shaped steel section, and the slabs rest on the two vertical webs. In both cases, the lower plate accomplishes all the tasks of the classical formworks. An arch-shaped configuration of the truss-reinforced steel-concrete composite beam is sometimes adopted for special buildings (Figure 3). One of the most attractive features of these particular structural members is the partially precast nature, which makes easier and speeds up the realization of large civil constructions. In fact, all the steel components are made in the assembly shops and moved toward the building site where they are placed between pairs of columns by means of cranes (Figure 4 and Figure 5). In these conditions, the beams behave like classical steel structures and the corresponding mechanical model to be adopted is that of a simply supported beam. Once the truss element is mounted, the slabs are positioned and the concrete is cast in place. After the hardening of concrete, the structural element does not behave anymore as a steel truss structure, rather, as a steel-concrete composite beam, Quaranta et al. [4].

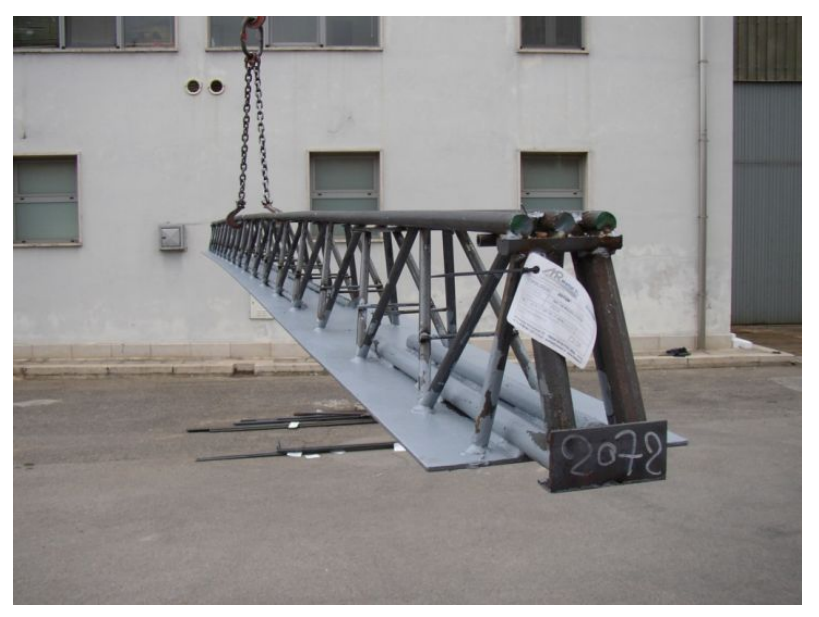

Figure 1. The special truss structure which provides the final reinforcement of the composite steel-concrete beam.

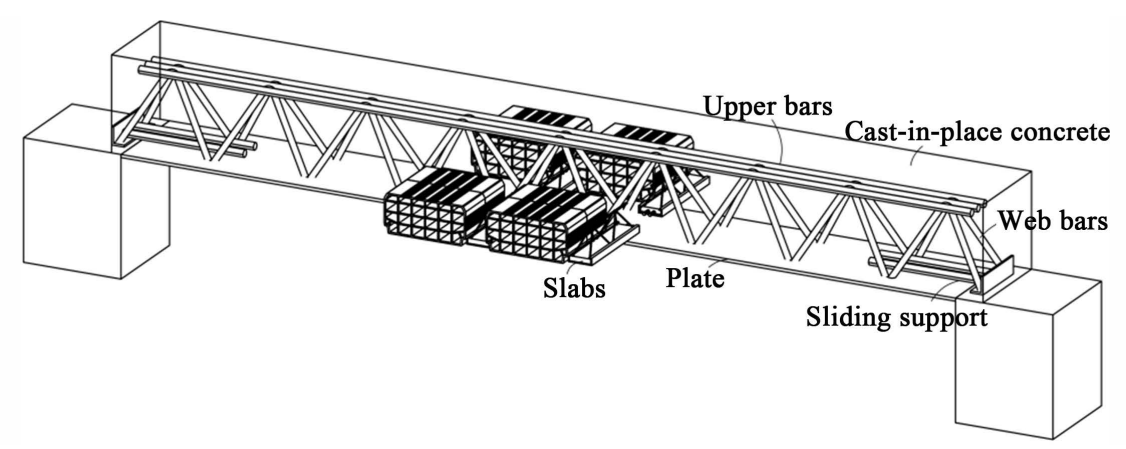

Figure 2. Reinforcing steel truss structure: main element and slabs. 


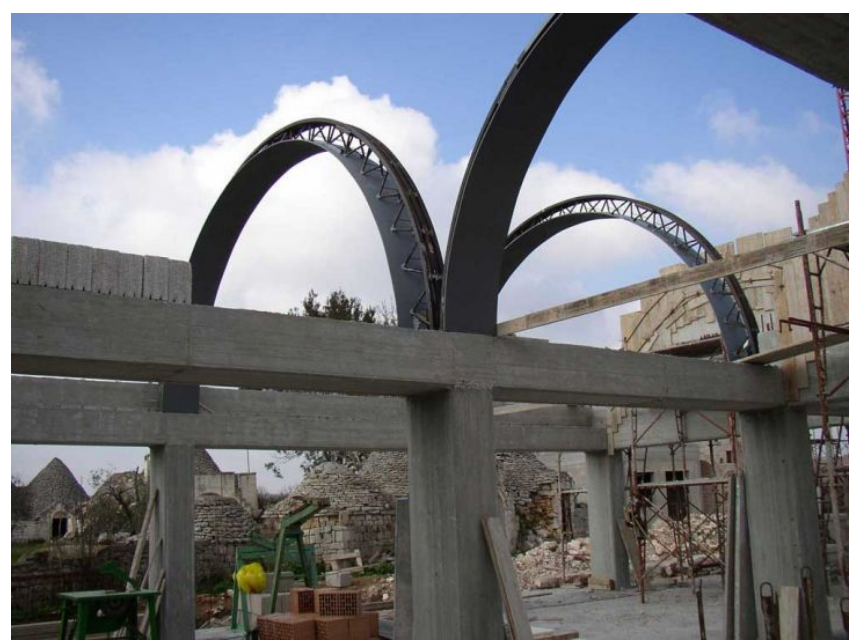

Figure 3. Reinforcing element in steel-concrete composite arches.

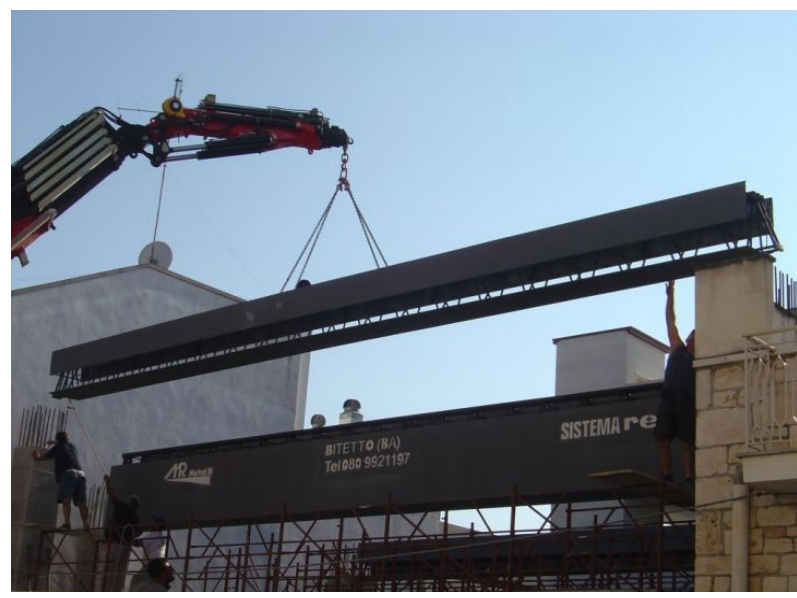

Figure 4. Moving and positioning of the steel truss structure by means of crane. Thin vertical flanges are welded at both sides to contain the concrete filling.

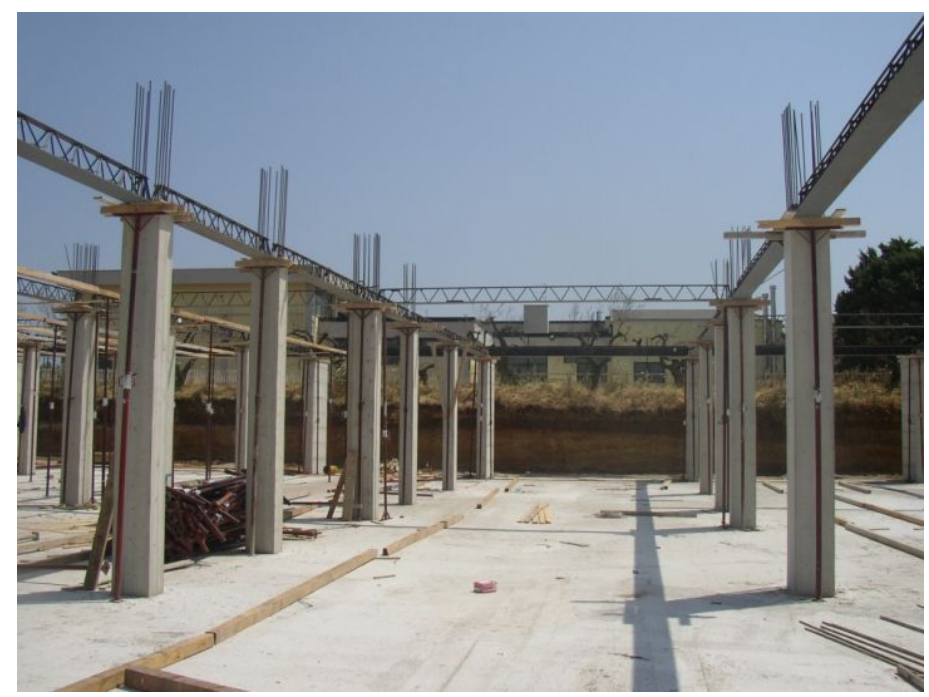

Figure 5. Reinforcing steel truss structures after positioning on the columns. 
Since the steel truss structure is self-supporting, only few props are usually recommended close to the columns whereas no supports are required along the span of the beam, as shown in Figure 5 . The reduction of the props number diminishes significantly the obstacles, which are the most important sources of risk and injury in building sites. Moreover, all activities within the construction site are considerably faster, and larger free space is made available for further construction activities. Current applications show that truss-reinforced steel-concrete composite beams can sustain larger loads and allow longer spans than ordinary reinforced concrete beams. In order to comply with serviceability limit states for displacement/deformation control, the steel truss structure is frequently assembled by imposing a suitable camber, so as to reduce long-term deformations of the composite steel-concrete beam. Overall, all these features have made this composite beam structures rather popular in Italy. Although this technology is gaining interest in Italy, well-codified structural design formulas and rules are not available yet. This entails that the mechanical behavior of truss-reinforced steel-concrete composite beams can be analyzed by comparison with structural models of classical reinforced concrete beams and steel and concrete composite beams (Mark [5], Sanches Júnior and Venturini [6]). Therefore, a systematic experimental and theoretical investigation about this class of steel-concrete structural elements has recently started with the aim of defining a comprehensive set of design tools for practitioners. For instance, numerical finite element based analyses and a closed-form solution to evaluate the elastic critical moment for lateral-torsional buckling of the steel truss structure have been presented in Trentadue et al. [7] and [8], respectively. An experimental study about the shear capacity of the final truss-reinforced composite steel-concrete beams is reported in Petrone et al. [9] [10]. The effectiveness of important construction details for earthquake-resistant structural design has not been addressed so far, with the possible exception of some preliminary experimental studies about beam-column joints subjected to cyclic loading, Scotta and Tesser [11].

In order to provide further design tools, this work is primarily concerned with the role of the diagonal bars on bending stiffness. To this end, referring to the studies of Nie et al. [12] about steel and concrete composite beams and Castel et al. [13] about cracked reinforced concrete beams, a closed-form solution for the evaluation of the equivalent final bending stiffness is derived as an effective design tool for practitioners. Subsequently, the influence of geometrical and mechanical characteristics of the shear reinforcement is investigated. Finally, results obtained from parametric and numerical analyses are discussed.

\section{Truss-Reinforced Composite Steel-Concrete Beams}

Because of the construction method, two different working stages can be clearly identified (Figure 6). During the first transitory stage (named S1), the structure is a simply-supported steel truss beam, which is loaded by its self-weight, the precast floor system weight and the weight of fresh concrete filling. In this transitory stage, the structural design of the beam is based on limit states typical of steel structures, such as bending and axial force resistance of cross-sections, local and global instability. After concrete hardening, a stage (S2) is achieved in which the structural member behaves as a special steel-concrete composite beam. This is a permanent condition

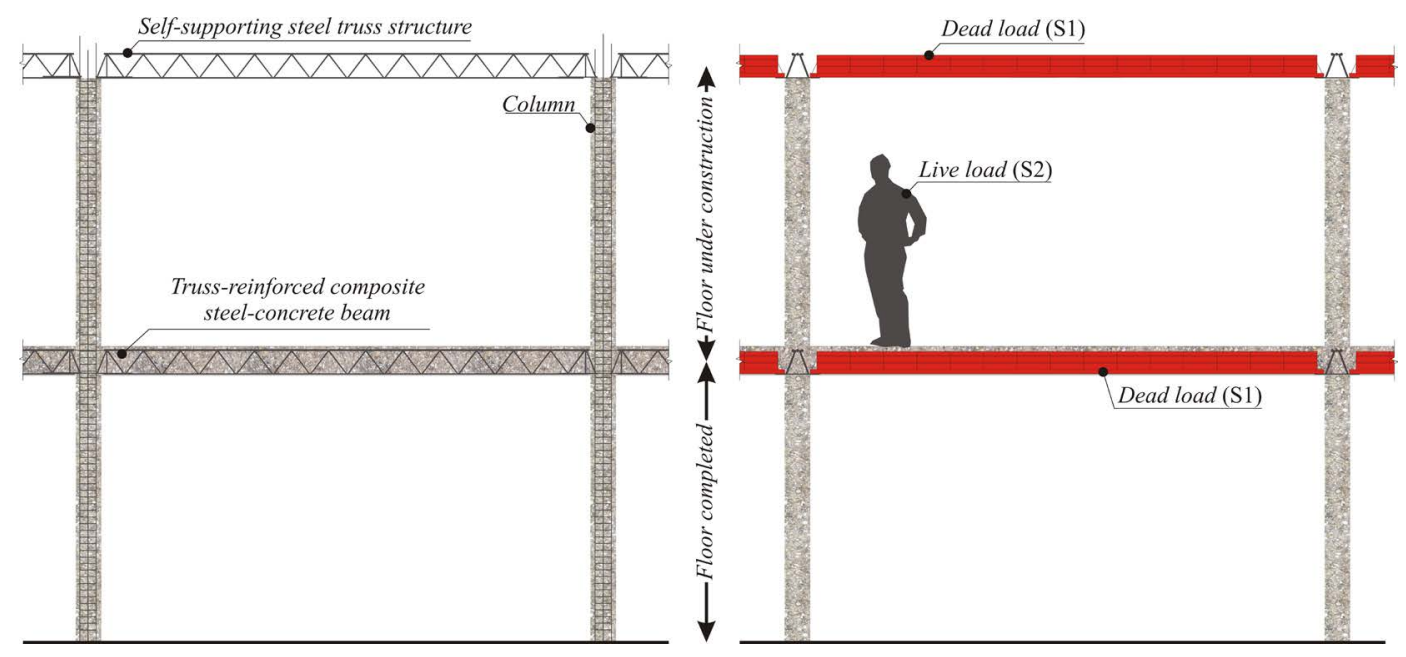

Figure 6. Two working stages of the composite steel-concrete beam. 
in which all further actions and environmental factors are to be considered. Therefore, S2 needs a global analysis of the structure that the beam belongs to. Moreover, the structural design in S2 depends on limit states typical of steel-concrete composite structures, such as ultimate limit states (i.e., combined bending moment-axial force, shear, torsion) and serviceability limit states (i.e., stress limitation, crack control, deflection control). It must be remarked that, in S2, the steel truss member is not stress-free, since it is preloaded by the weights acting in S1. As a consequence, the structural design in S2 depends on the pre-stress condition due to the loads in S1. In this paper, the analysis is limited to the special reinforcing steel truss beams having the geometry depicted in Figure 7 , one of the most typical in ordinary constructions. The considered beam section has two smooth diagonal bars and three smooth upper bars. The spacing $2 \delta$ between the diagonal bars is constant over the beam span.

\section{Bending Stiffness Calculation}

Since truss-reinforced composite steel-concrete beams are frequently adopted to cover large spans, the assessment of the bending stiffness becomes a critical design point for practitioners. Therefore, a closed-form analytical solution would be an effective tool for rapid hand calculations as well as for checking finite element results. In this perspective, the contribution due to welded diagonal steel bars should be properly considered in order to avoid unpractical underestimation of the total bending stiffness. It must be pointed out that viscous effects occur in S2 only, thus causing a significant reduction of total bending deformation.

A beam slice with length equal to $2 \delta$ subjected to bending deformation is now considered (Figure 8). It is assumed that orthogonal sections remain plane under bending deformation. This assumption implies that the diagonal bars are stressed, thus contributing to the final bending stiffness. The relative bending rotation $\theta$ between the two ends of the beam element can be determined as follows:

$$
\theta=2 \delta \chi=2 \delta\left(\frac{M}{E J_{e q}}\right)
$$

where $\chi$ is the bending curvature, $E$ is the elastic modulus, $E J_{e q}$ is the bending stiffness ( $J_{e q}$ is the moment of inertia), $M$ is the bending moment. The total elastic energy $E_{\text {tot }}$ of this beam element is:

$$
E_{\text {tot }}=\frac{1}{2} M \theta=\frac{1}{2}\left(E J_{e q} \chi\right)(2 \chi \delta)
$$

The total elastic energy $E_{\text {tot }}$ is due to the deformation of, both, steel bars and concrete. It can be written as the sum of two terms: the first one is obtained by neglecting the diagonal bars contribution through the classical reinforced concrete beams theory, while the second term is due to the deformation of the diagonal bars:

$$
E_{\text {tot }}=E J \chi^{2} \delta+E_{\text {diag }}
$$

where $E J$ is the bending stiffness of a section in which the longitudinal steel reinforcement only is considered and $E_{\text {diag }}$ is the elastic energy due to the deformation of the diagonal bars.

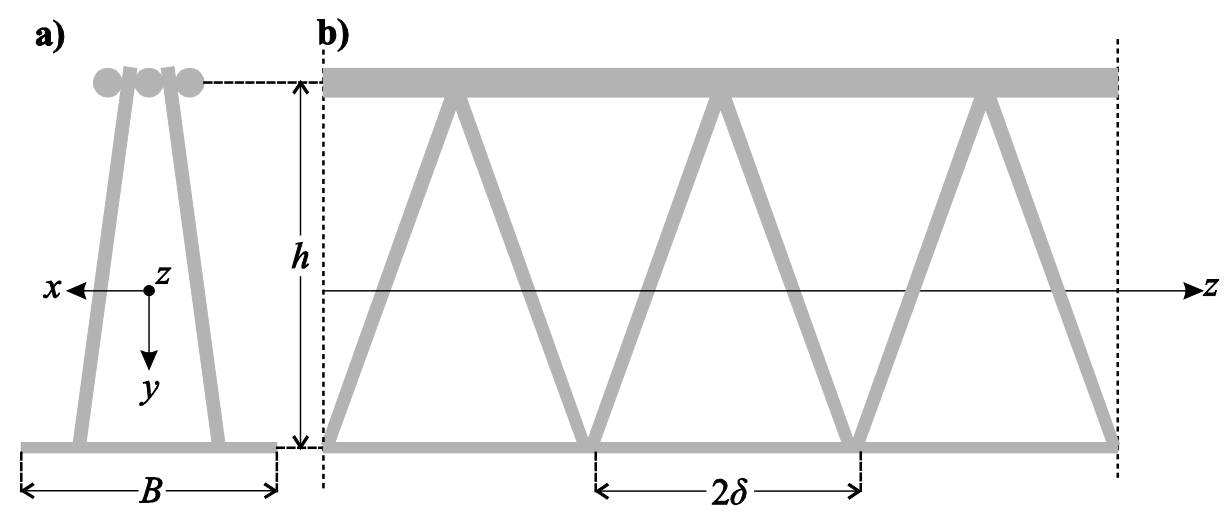

Figure 7. Layout of the steel truss structure: a) transversal section; b) longitudinal section. 
For the sake of simplicity, bond between diagonal bars and concrete is here neglected and thus the longitudinal strain in the diagonal bar is kept constant. By doing so, a conservative estimation of the bending stiffness is obtained. The elastic energy due to the deformation of the diagonal bars is then evaluated as follows:

$$
E_{\text {diag }}=\frac{1}{2}\left(2 m_{\text {diag }}\right) N_{\text {diag }} \Delta l_{\text {diag }}=m_{\text {diag }} \frac{E A_{\text {diag }} \Delta l_{\text {diag }}}{l_{\text {diag }}} \Delta l_{\text {diag }}
$$

where $N_{\text {diag }}$ is the axial force in the diagonal bars, $\Delta l_{\text {diag }}$ is the bar elongation due to bending deformation, $2 m_{\text {diag }}$ is the number of diagonal bars in the beam element of length $2 \delta, l_{\text {diag }}$ is the bar length, and $A_{\text {diag }}$ is the cross area of a single diagonal bar. On considering proper kinematic relationships (Figure 8):

$$
\begin{gathered}
\Delta l_{\text {diag }}=\Delta z \sin \alpha=\Delta z \frac{\delta}{l_{\text {diag }}} \\
\Delta z=\left(d-y_{n}\right) \chi \delta \\
\Delta l_{\text {diag }}=\left(d-y_{n}\right) \chi \frac{\delta^{2}}{l_{\text {diag }}}
\end{gathered}
$$

the elastic energy due to the deformation of the diagonal bars is rewritten as follows:

$$
\begin{aligned}
E_{\text {diag }} & =m_{\text {diag }} \frac{E \cdot A_{\text {diag }}}{l_{\text {diag }}}\left[\left(d-y_{n}\right) \chi \frac{\delta^{2}}{l_{\text {diag }}}\right]^{2} \\
& =m_{\text {diag }} E A_{\text {diag }}\left(\frac{\delta}{l_{\text {diag }}}\right)^{3}\left(d-y_{n}\right)^{2} \chi^{2} \delta \\
& =m_{\text {diag }} E A_{\text {diag }} n_{z}^{3}\left(d-y_{n}\right)^{2} \chi^{2} \delta
\end{aligned}
$$

where $n_{z}$ is the cosine director of the diagonal bars along the $z$-axis. The total energy is then given by:

$$
E_{\text {tot }}=E J_{\text {eq }} \chi^{2} \delta=\left[E J+m_{\text {diag }} E A_{\text {diag }} n_{z}^{3}\left(d-y_{n}\right)^{2}\right] \chi^{2} \delta
$$

and finally

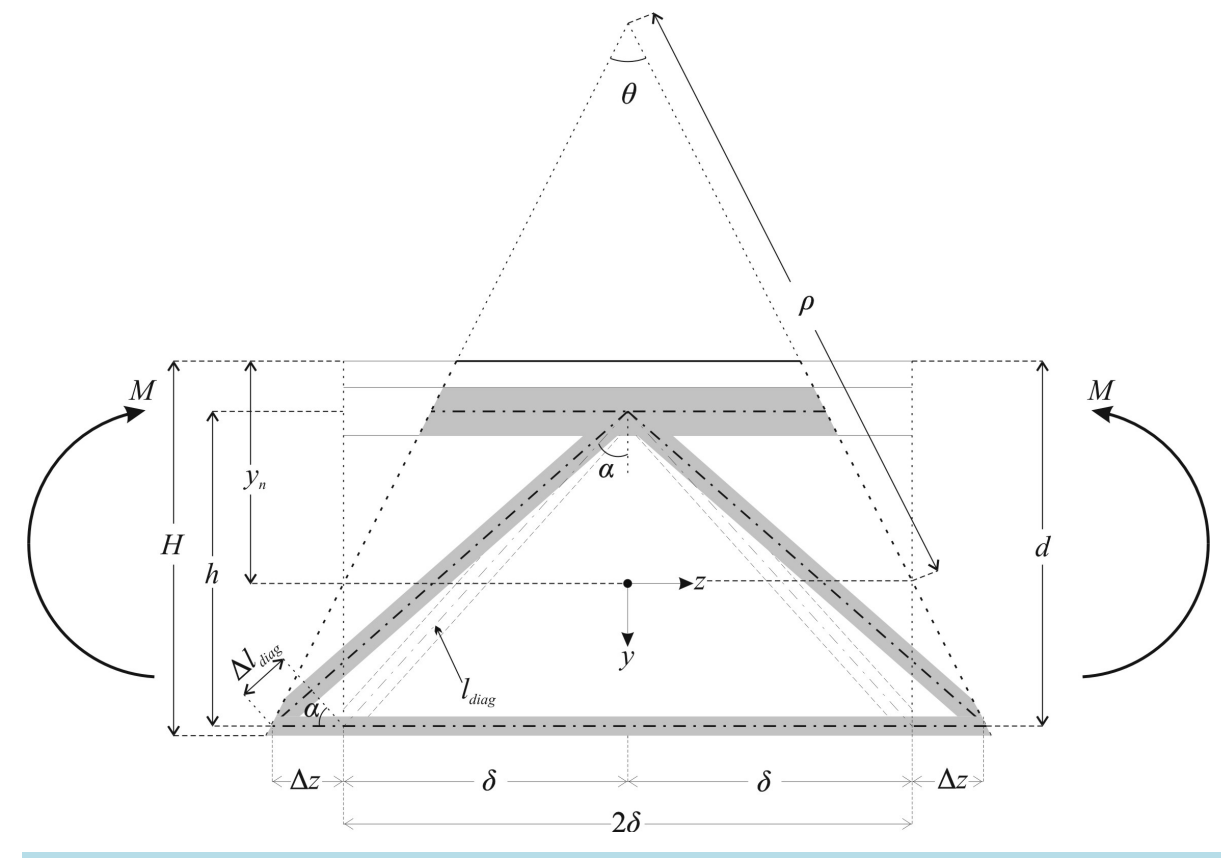

Figure 8. Beam element with length equal to $2 \delta$ subjected to bending deformation. 


$$
J_{e q}=J+m_{\text {diag }} A_{\text {diag }} n_{z}^{3}\left(d-y_{n}\right)^{2}
$$

The problem now reduces to the explicit calculation of the moment of inertia $J_{e q}$ for an assigned neutral axis position $y_{n}$. This calculation can be performed for, both, uncracked and cracked sections. In doing so, it is observed that the effect of the diagonal bar on the position of the center of mass is not the same for all transversal sections. Nonetheless, the contribution of the diagonal bars on the position of the center of mass is small, and thus neglected.

For an uncracked section such as that shown in Figure 9, the symbol G denotes the center of the concrete section whereas G' indicates the center of a concrete-equivalent section. The concrete-equivalent section is obtained by means of the coefficient $n_{E}=E_{s} / E_{c}$ (the ratio between the Young modulus of steel and concrete).

The distance $y_{n}$ of the center G' from the upper chord of the transversal section is:

$$
y_{n}=\frac{\left(\frac{B H^{2}}{2}\right)+n_{E} d A_{i p}+n_{E} c A_{u c}}{B H+n_{E}\left(A_{i p}+A_{u c}\right)}
$$

where $A_{l p}$ is the cross-section area of lower plate and $A_{u c}$ is the total cross area of the upper chord. The moment of inertia of the uncracked section is:

$$
J_{e q}=\frac{B H^{3}}{12}+B H\left(\frac{H}{2}-y_{n}\right)^{2}+n_{E}\left(A_{i p}+n_{z}^{3} m_{\text {diag }} A_{\text {diag }}\right)\left(d-y_{n}\right)^{2}+n_{E} A_{u c}\left(y_{n}-c\right)^{2}
$$

For cracked section (Figure 10), the neutral axis position is:

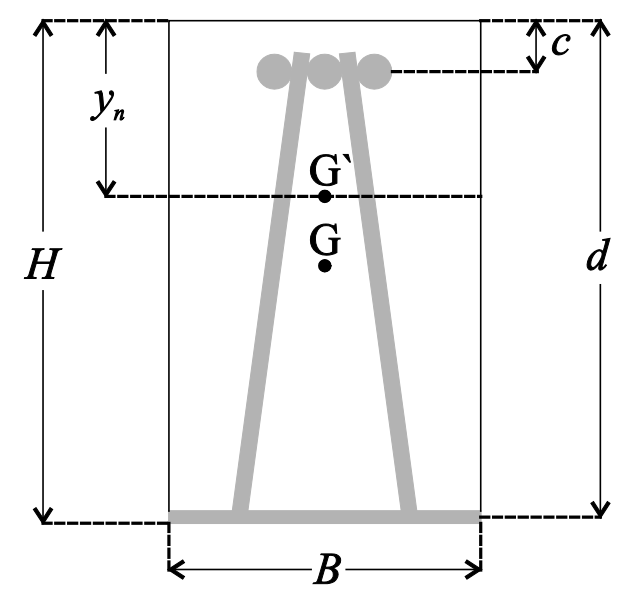

Figure 9. Uncracked transversal section.

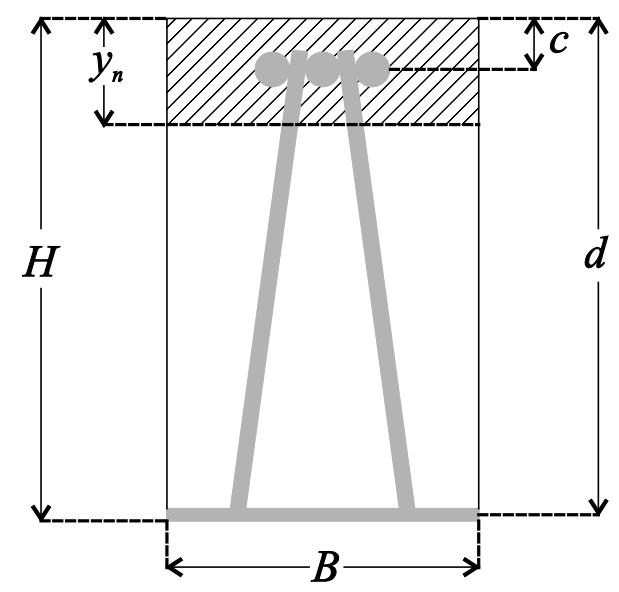

Figure 10. Cracked transversal section. 


$$
y_{n}=\frac{n_{E}\left(A_{l p}+A_{u c}\right)}{B}\left[-1+\sqrt{1+\frac{2 B\left(A_{l p} d+A_{u c} c\right)}{n_{E}\left(A_{l p}+A_{u c}\right)^{2}}}\right]
$$

whereas the moment of inertia is:

$$
J_{e q}=\frac{B y_{n}^{3}}{3}+n_{E}\left(A_{t p}+n_{z}^{3} m_{\text {diag }} A_{\text {diag }}\right)\left(d-y_{n}\right)^{2}+n_{E} A_{u c}\left(y_{n}-c\right)^{2}
$$

\section{Parametric Analysis}

Dimensionless formulas and charts are useful for rapid calculations and can support parametric analyses aimed at highlighting the role of geometrical and mechanical characteristics of the shear reinforcement on the final bending stiffness. The parametric analysis developed in the following is limited to cracked sections only, as they represent the most significant situation for practical design applications. Moreover, the comparison between Equation (12) and Equation (14) demonstrates that the effect of shear reinforcement on the final bending stiffness is more pronounced in cracked sections rather than in uncracked ones, as expected.

In order to perform the parametric analysis, the following quantities have been taken into account:

- $\delta$ is the half spacing of steel bars (referring to the condition $\alpha=\theta$, typical in practical cases);

- $B$ is $t$ the cross-section width of the composite beam;

- $\zeta=d / \delta$ is the aspect ratio ${ }^{1}$, where $d$ is the effective depth of the beam and $\delta$ has the meaning explained above;

- $c=0.1 \cdot d$ is the concrete cover.

The relevant geometrical characteristics of the reinforcement are expressed as follows:

- $A_{s b}=m_{\text {diag }} \pi \phi_{s b}^{2} / 4=n_{s b} A_{\text {diag }}$ is the area of the shear reinforcement, where $m_{\text {diag }}$ is the number of bars and $\phi_{s b}$ is the diameter of the bars;

- $A_{u c}=n_{u c} \pi \phi_{u c}^{2} / 4$ is the area of the upper chord reinforcement, where $n_{u c}$ is the number of bars and $\phi_{u c}$ is the diameter of the bars;

- $A_{l p}=B \cdot t$ is the area of the lower steel plate, where $t$ is its thickness and $B$ has the meaning explained above.

Finally, the dimensionless quantity $\omega$ is introduced in order to correlate the amount of lower longitudinal reinforcement with the shear one. Thus, $\omega$ represents the mechanical ratio between the shear reinforcement and the lower plate, as shown in the following:

$$
\omega=\frac{f_{y, s b} \cdot A_{s b}}{f_{y, l p} \cdot A_{l p}}
$$

So doing, the equivalent area of the lower longitudinal reinforcement $A_{e q}$ can be expressed as function of both $\zeta$ and $\omega$, thus obtaining:

$$
A_{e q}(\zeta, \omega)=A_{l p}\left(1+\omega \cdot \cos (\operatorname{atan}(\zeta))^{3}\right)
$$

and

$$
y_{n}(\zeta, \omega)=\frac{1}{B}\left[-n_{E}\left(A_{u c}+A_{e q}(\zeta, \omega)\right)+\sqrt{n_{E}^{2}\left(A_{u c}+A_{e q}(\zeta, \omega)\right)^{2}+2 B n_{E}\left(A_{u c} c+d_{s} A_{e q}(\zeta, \omega)\right)}\right]
$$

Then, the moment of inertia $J(\zeta, \omega)$ and the equivalent one $J_{e q}(\zeta, \omega)$, which takes into account the shear reinforcement contribution, can be rewritten as follows, respectively:

$$
J(\zeta, \omega)=\frac{B\left(y_{n}(\zeta, \omega)\right)^{3}}{3}+n_{E}\left[A_{i p}\left(d-y_{n}(\zeta, \omega)\right)^{2}+A_{u c}\left(y_{n}(\zeta, \omega)-c\right)^{2}\right]
$$

\footnotetext{
${ }^{1}$ Note that in case of evaluating $J_{e q}$ of an existing structure, see (19), the value of $\zeta$ can be calculated referring to the known values $d$ and $\delta$. Otherwise, in case of design that aims at a certain value of the equivalent bending stiffness, the sizing of the cross-section depth can be conducted referring to a certain value of $\zeta$, so that $d$ can be defined as a function of $\zeta: d(\zeta)=\zeta \cdot \delta$
} 


$$
J_{e q}(\zeta, \omega)=\frac{B\left(y_{n}(\zeta, \omega)\right)^{3}}{3}+n_{E}\left[A_{e q}\left(d-y_{n}(\zeta, \omega)\right)^{2}+A_{u c}\left(y_{n}(\zeta, \omega)-c\right)^{2}\right]
$$

The parameter:

$$
\vartheta(\zeta, \omega)=\frac{J_{e q}(\zeta, \omega)}{J(\zeta, \omega)}
$$

is considered, in order to investigate the role of the spatial shear reinforcement on the final bending stiffness of the beam. Figure 11 shows the variation of $\vartheta(\zeta, \omega)$ as function of $\zeta$ only, for different values of $\omega$. The results shown in this chart demonstrate that the shear reinforcement can lead to significant increments in the bending stiffness of the beam. Therefore, ignoring diagonal bars in the evaluation of the bending stiffness might give rise to a too conservative design, with severe consequence on the final project cost. Figure 11 also demonstrates that the shear reinforcement influence on $J_{e q}(\zeta, \omega)$ decreases as $\zeta$ increases. Figure 12 shows the variation of $\vartheta(\zeta, \omega)$ as a function of $\omega$ only, for different values of $\zeta$. These curves prove that $J_{e q}(\zeta, \omega)$ increases as $\omega$ grows up.

It is observed that the mechanical ratio $\omega$ influence on $J_{e q}(\zeta, \omega)$ is very relevant for small and medium values of $\zeta$, which implies that both geometrical and mechanical characteristics of the shear reinforcement play a crucial role in determining the beam bending stiffness. To better understand the influence of geometrical and mechanical characteristics of the cross-section on the bending stiffness, the variation of $\vartheta(\zeta, \omega)$ has been analyzed referring to theoretical values of $\omega$, see Figure 13. The curves show that the function $\vartheta(\zeta, \omega)$ has an increasing trend until a certain maximum value, different for each $\zeta$ : in fact as the shear reinforcement increases, also the value of $y_{n}$ grows up, see (17) and Figure 14, until the maximum value, which equals the

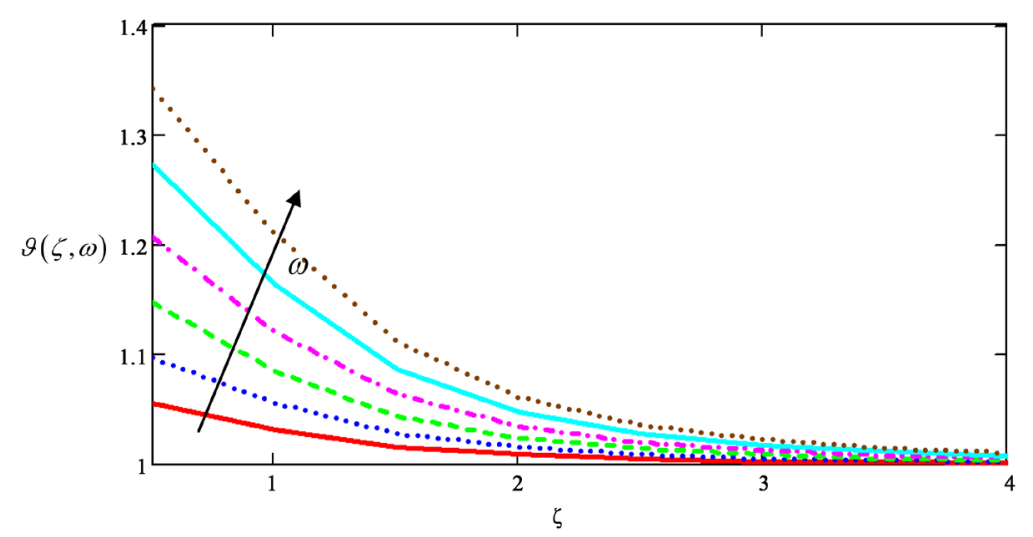

Figure 11. Variation of $\vartheta(\zeta, \omega)$ as function of $\zeta$.

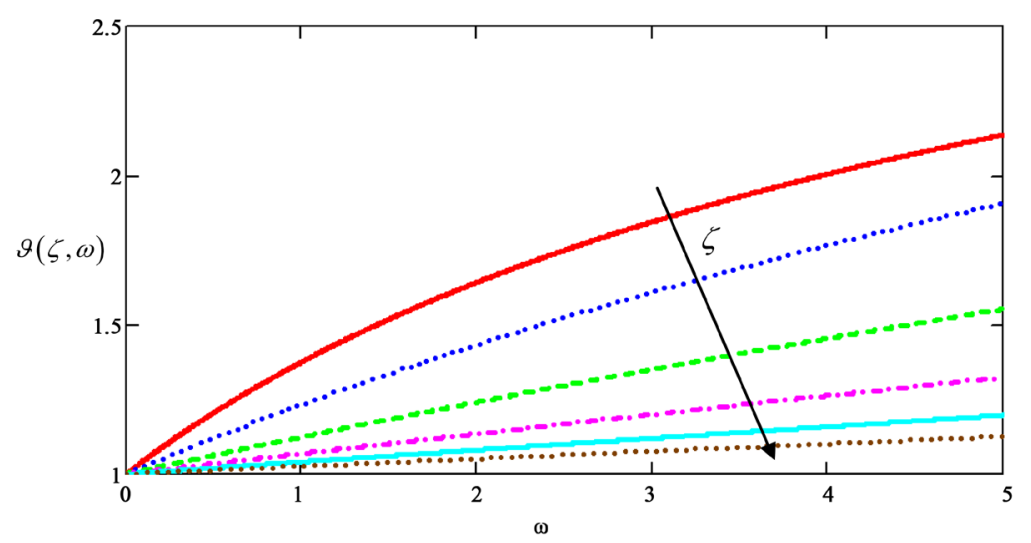

Figure 12. Variation of $\vartheta(\zeta, \omega)$ as function of $\omega$. 


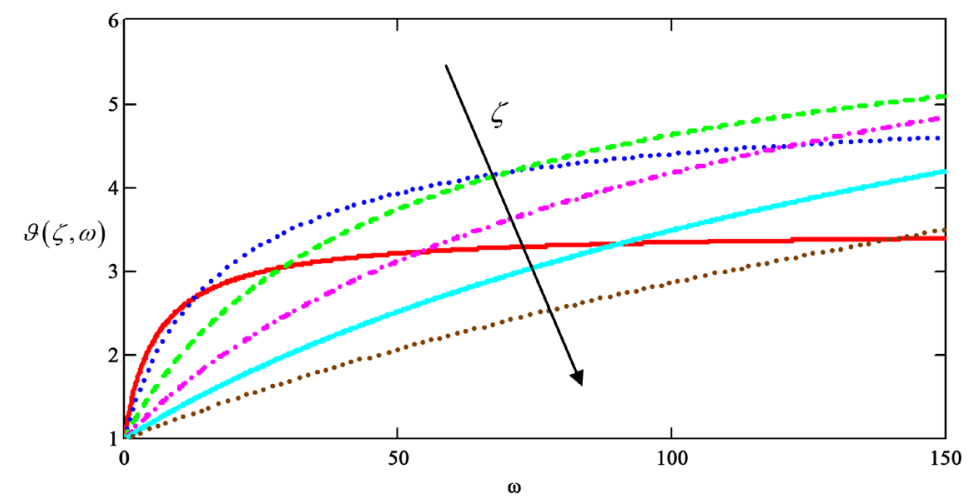

Figure 13. Variation of $\vartheta(\zeta, \omega)$ as function of theoretical values of $\omega$.

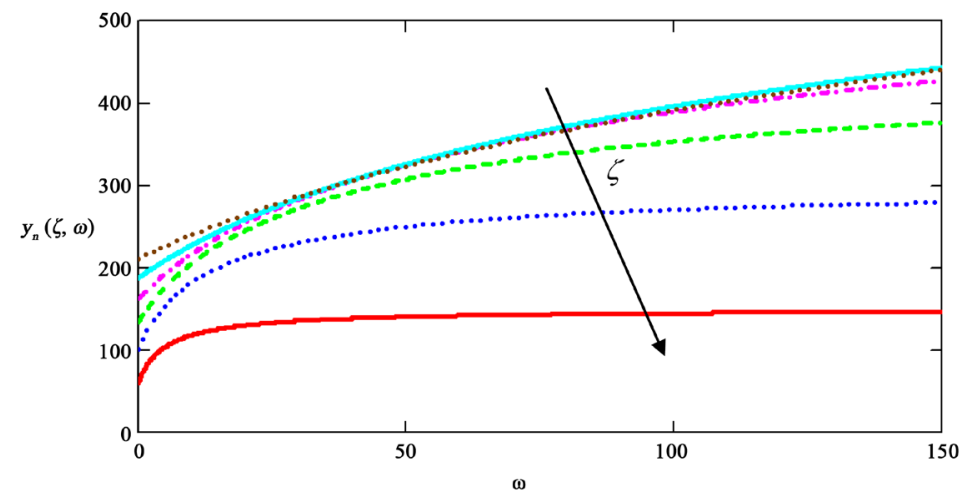

Figure 14. Variation of $y_{n}(\zeta, \omega)$.

effective depth of the cross section. So, the contribution of the concrete compressive chord to the inertia moment increases when $\omega$ grows up because of the increasing of $y_{n}$. Then the influence of further increment of $\omega$ the shear reinforcement on the moment of inertia becomes insignificant and the ratio $\vartheta(\zeta, \omega)$ tends to a constant value.

Therefore, this parametric study has highlighted the effects of, both, geometrical and mechanical properties of the shear reinforcement on the final bending stiffness of the beam. The analysis confirms that the spatial shear reinforcement gives a significant contribution to the bending stiffness in such class of composite beams.

The closed-form solutions here presented for $J_{e q}$ can be used for simplified hand calculations. For instance, they can be adopted to assess serviceability limit states. Moreover, the parameter $\vartheta(\zeta, \omega)$ can be conveniently adopted in computer-aided structural analyses. In fact, commercial finite element codes implement built-in reinforced concrete sections for structural analysis. These reinforced concrete sections can be still used for the analysis of frame structures with truss-reinforced steel-concrete composite beams, provided the moment of inertia is properly increased by using the parameter $\vartheta(\zeta, \omega)$.

\section{Validation}

The formulation here proposed for evaluating the equivalent inertia moment $J_{e q}$ has been verified by comparison with numerical analyses, whose results are summarized in load-controlled pushover curves.

The analyses have been performed referring to the simplified structural models depicted in Figure 15, which shows the representative half-length of the beam element, with and without shear reinforcement, at cracked stage and subjected to the horizontal forces $l_{1}$ and $l_{2}$, and to the vertical force $V$ that ensures the equilibrium condition.

The moments of inertia of both structural elements have been computed before either the yielding of steel or the crushing of concrete, referring to the elastic branch of the moment-rotation graphs $(M, \varphi)$ obtained from pushover analyses. 


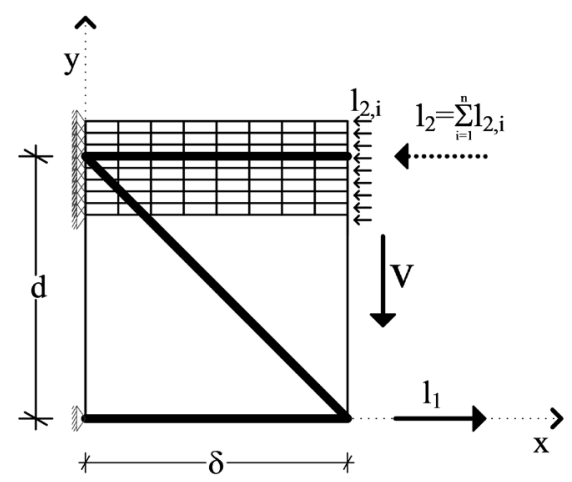

(a)

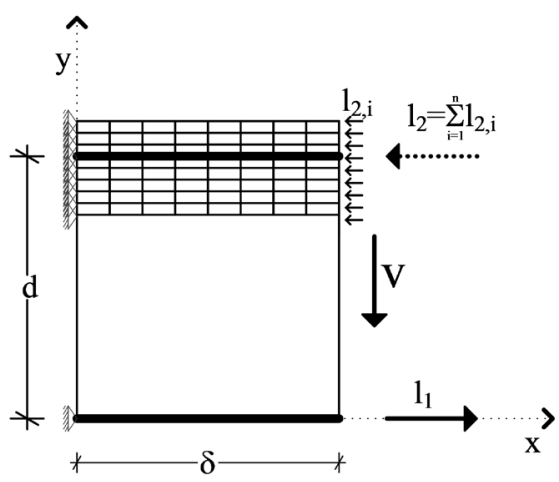

(b)

Figure 15. Structural models: (a) with shear reinforcement; (b) without shear reinforcement.

The study has been conducted on the following five cases, representing the dimensions of common real structures, when $\omega=0.785$ :

- Case 1: $\delta=300 \mathrm{~mm} ; z_{1}=200 \mathrm{~mm} \rightarrow \zeta_{1}=0.67$;

- Case 2: $\delta=300 \mathrm{~mm} ; z_{2}=250 \mathrm{~mm} \rightarrow \zeta_{2}=0.83$;

- Case 3: $\delta=300 \mathrm{~mm} ; z_{3}=300 \mathrm{~mm} \rightarrow \zeta_{3}=1.00$;

- Case 4: $\delta=300 \mathrm{~mm} ; z_{4}=350 \mathrm{~mm} \rightarrow \zeta_{4}=1.17$;

- Case 5: $\delta=300 \mathrm{~mm} ; z_{5}=400 \mathrm{~mm} \rightarrow \zeta_{5}=1.34$.

The analysis of Case 1 , Case 3 and Case 5 will be presented in detail thereafter.

Figures 16-18, representing moment-rotation graphs of the cross-section with and without shear reinforcement for Case 1, Case 3 and Case 5, respectively, clearly show that the rotation of the cross-section with shear reinforcement is lower than the rotation of the cross-section without shear reinforcement at the yielding point and for those cases where the rotation is comparable, the moment of the beam with shear reinforcement is significantly greater than the moment of the same beam without shear reinforcement.

For each case, see Figures 16-18, we have:

- Case 1: $\varphi_{w /}=0.004, \varphi_{w / o}=0.005-M_{w /} \sim 144,000 \mathrm{kN} \cdot \mathrm{mm}, M_{w / o} \sim 137,500 \mathrm{kN} \cdot \mathrm{mm}$;

- Case 3: $\varphi_{w /} \sim \varphi_{w / o}=0.0032-M_{w /} \sim 272.000 \mathrm{kN} \cdot \mathrm{mm}, M_{w / o} \sim 230.000 \mathrm{kN} \cdot \mathrm{mm}$;

- Case 5: $\varphi_{w /}=0.0028, \varphi_{w / o}=0.0023-M_{w /} \sim 389.000 \mathrm{kN} \cdot \mathrm{mm}, M_{w / o} \sim 304.000 \mathrm{kN} \cdot \mathrm{mm}$.

The contribution of shear reinforcement to the bending stiffness is evaluated through the ratio between inertia moment with and without shear reinforcement, giving the following results:

$$
\begin{aligned}
& \zeta_{1}=0.67 \rightarrow \frac{J_{s r}}{J}=1.23 \\
& \zeta_{2}=0.83 \rightarrow \frac{J_{s r}}{J}=1.19 \\
& \zeta_{3}=1.00 \rightarrow \frac{J_{s r}}{J}=1.18 \\
& \zeta_{4}=1.17 \rightarrow \frac{J_{s r}}{J}=1.14 \\
& \zeta_{5}=1.34 \rightarrow \frac{J_{s r}}{J}=1.12
\end{aligned}
$$

The values of the ratio $J_{s r} / J$ so obrained confirm that the inertia moment of the beam increases significantly, up to $\sim 20 \%$, thanks to the shear reinforcement contribution.

Moreover, to verify the accuracy of the proposed closed-form equation in evaluating the equivalent moment of inertia $J_{e q}$, see (19), the values of $J_{s h}$ obtained from pushover analyses have been used as comparison. The results are summarized in Table 1.

The results show that the proposed formulation allows an accurate evaluation of the equivalent inertia moment, with an approximation of $1 \div 2 \%$. 


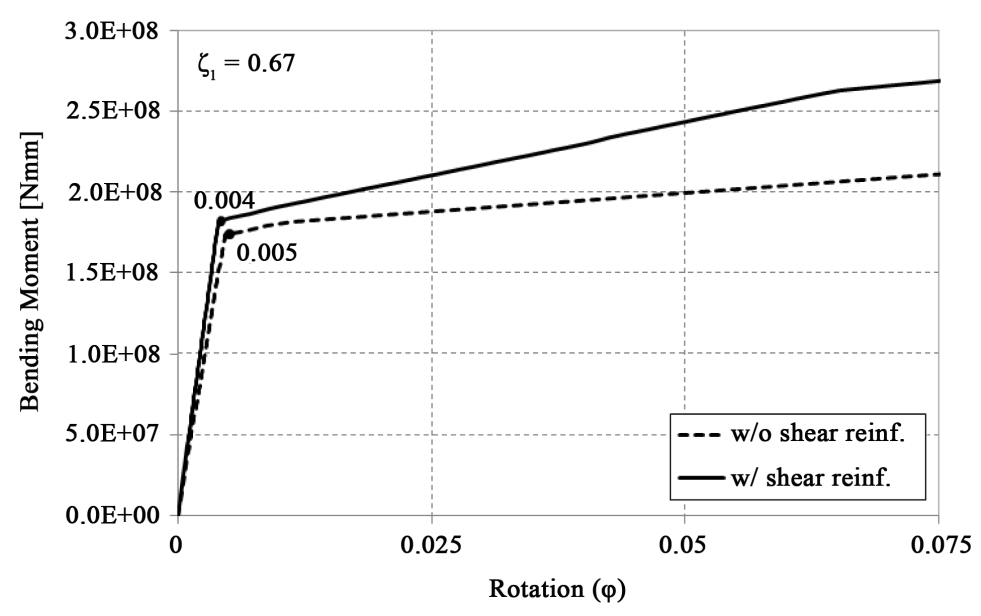

Figure 16. Comparison: $M-\varphi$ graph $\mathrm{w} /$ and w/o shear reinforcement for $\zeta=0.67$.

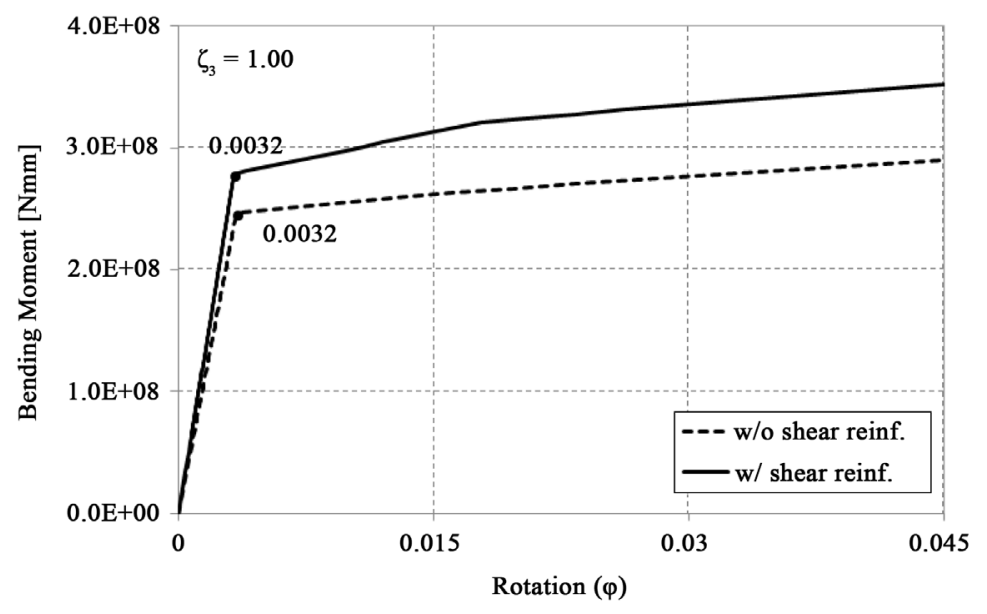

Figure 17. Comparison: $M-\varphi$ graph $\mathrm{w} /$ and w/o shear reinforcement for $\zeta=1.00$.

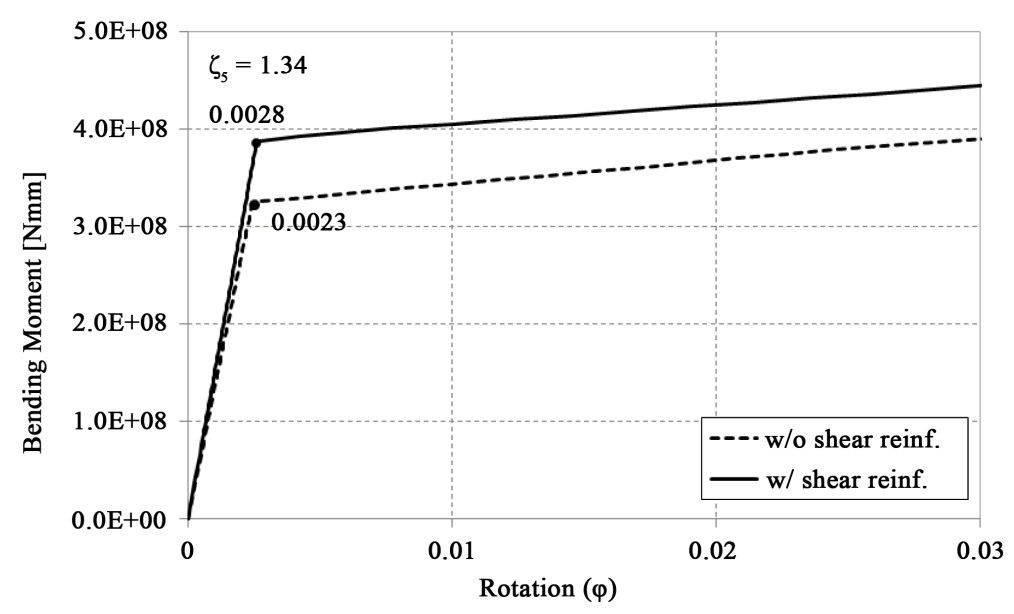

Figure 18. Comparison: $M-\varphi$ graph $\mathrm{w} /$ and w/o shear reinforcement for $\zeta=1.34$. 
Therefore these structures can be conveniently modeled by making use of $A_{e q}$, see (16) and Figure 19, as an alternative to varying the values if the inerta moment. In confirmation of this, Figures 20-22, showing $M-\varphi$ function for Case 1, Case 2 and case, respectively, prove that both the model with shear reinforcement and the model with the equivalent area $A_{e q}$ give the same results in terms of rotation of the cross-section in the elastic range.

Table 2 summarizes the comparison between $J_{\text {sh }}$ and $J_{\text {eq }}$, obtained from the numerical analyses on the

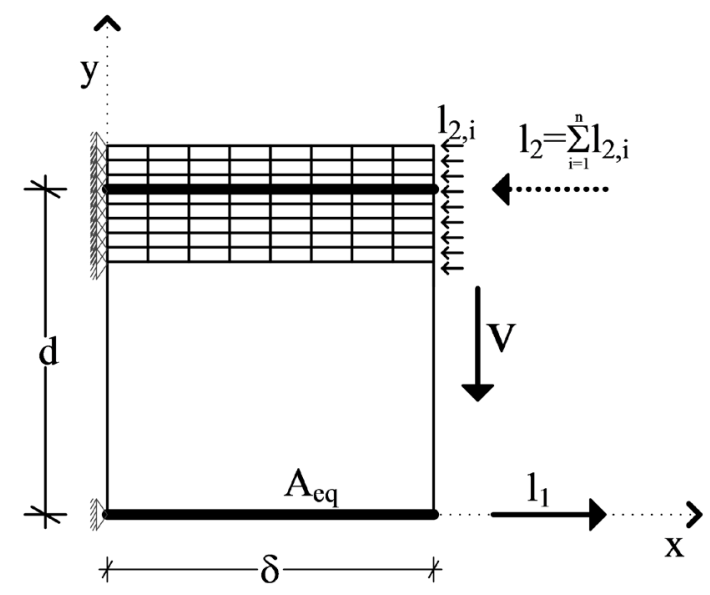

Figure 19. Structural model- $A_{e q}$.

Table 1. Comparison between numerical analysis $J_{\text {sh }}$ and analytical equation $J_{e q}$.

\begin{tabular}{cccc} 
& $\begin{array}{c}J_{\text {sh }} \\
{\left[\mathrm{mm}^{4}\right]}\end{array}$ & $\begin{array}{c}J_{\text {eq }} \\
{\left[\mathrm{mm}^{4}\right]}\end{array}$ & $J_{\text {eq }} / J_{\text {sh }}$ \\
\cline { 2 - 3 } & Numerical analysis & Enalytical equation-Aeq & 1.01 \\
\hline Case 1 & $3.673 \mathrm{E}+08$ & $3.712 \mathrm{E}+08$ & 1.02 \\
Case 2 & $5.256 \mathrm{E}+08$ & $5.343 \mathrm{E}+08$ & 1.01 \\
Case 3 & $7.159 \mathrm{E}+08$ & $7.238 \mathrm{E}+08$ & 1.02 \\
Case 4 & $9.799 \mathrm{E}+08$ & $9.980 \mathrm{E}+08$ & 1.02 \\
\hline
\end{tabular}

Table 2. Numerical analyses: Shear reinforcement—Equivalent area.

\begin{tabular}{|c|c|c|c|}
\hline & $\begin{array}{c}J_{s h} \\
{\left[\mathrm{~mm}^{4}\right]}\end{array}$ & $\begin{array}{c}J_{e q} \\
{\left[\mathrm{~mm}^{4}\right]}\end{array}$ & $J_{e q} / J_{s h}$ \\
\hline & Shear Reinforcement & Equivalent Area-Aeq & Error-\% \\
\hline Case1 & $3.673 E+08$ & $3.670 \mathrm{E}+08$ & 0.99 \\
\hline Case 2 & $5.256 \mathrm{E}+08$ & $5.254 \mathrm{E}+08$ & 0.99 \\
\hline Case 3 & $7.159 \mathrm{E}+08$ & $7.159 \mathrm{E}+08$ & $\sim 0.99$ \\
\hline Case 4 & $9.799 \mathrm{E}+08$ & $9.792 \mathrm{E}+08$ & 0.99 \\
\hline Case 5 & $1.255 \mathrm{E}+09$ & $1.254 \mathrm{E}+09$ & 0.99 \\
\hline
\end{tabular}




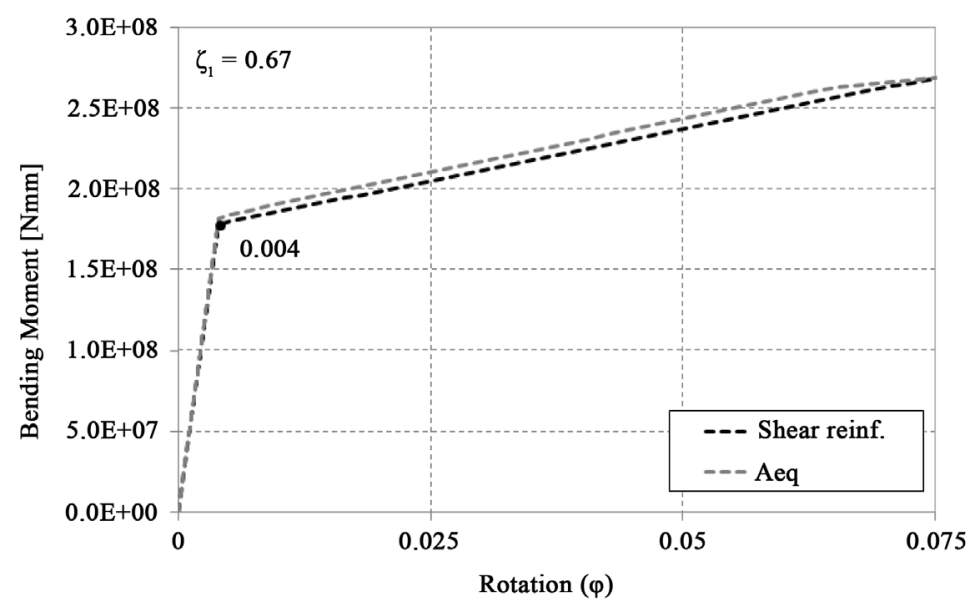

Figure 20. Comparison: $M-\varphi$ graph w/shear reinforcement and with $A_{e q}$ for $\zeta=0.67$.

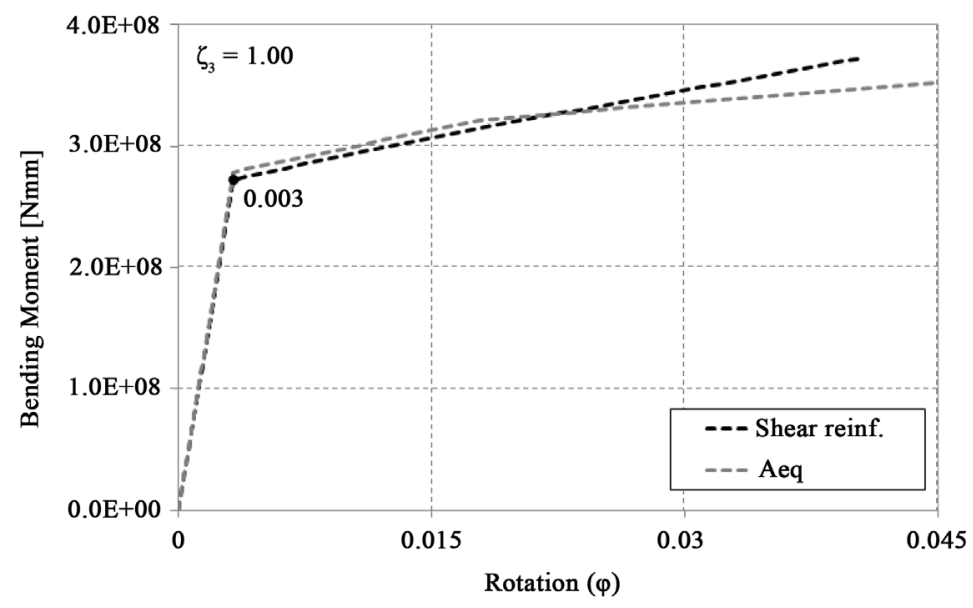

Figure 21. Comparison: $M-\varphi$ graph w/ shear reinforcement and with $A_{\text {eq }}$ for $\zeta=1.00$.

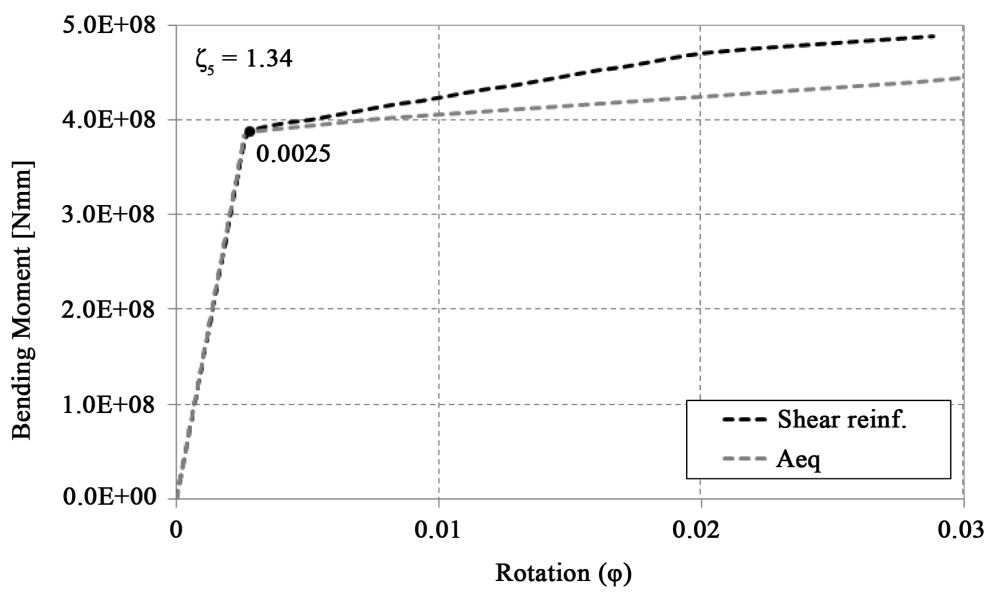

Figure 22. Comparison: $M-\varphi$ graph w/shear reinforcement and with $A_{e q}$ for $\zeta=1.34$. 
model with shear reinforcement and with the equivalent area, confirming a substantial equality of results.

Finally, note that the values derived from the numerical analyses can be also obtained referring to the graph of Figure 12. In fact, given the values of $\zeta$ and selected the curve of the assigned $\omega$, both known quantities since coming from the structural design, the value of $\vartheta(\zeta, \omega)$ can be easily found.

This allows practitioners to evaluate the increase of the inertia moment by checking the graph at the corresponding values of $\zeta$ and $\omega$.

\section{Conclusion}

This paper deals with a special steel-concrete composite beam, whose resisting element is a steel truss structure with a steel plate at the bottom, also meant to support a precast floor system. Within this framework, a useful and accurate closed-form equation for calculating the equivalent bending stiffness has been proposed along with a corresponding parametric formula (even in the form of graphic charts) that should represent rapid and easy design tool for practitioners. Sensitivity analyses and numerical applications demonstrated that the shear reinforcement provides a significant contribution to the final bending stiffness. As a consequence, ignoring such contribution can lead to over-conservative and anti-economical design solutions.

\section{Acknowledgements}

The authors wish to thank the managers of Metal. Ri s.r.l., mr A. Rizzi and V. Rizzi, as well as all its technical staff and Dr. Eng. Gianni Vitone (Senior Structural Designer) for their continuous support and technical competence in the field.

This work has been partially carried out under the program "Dipartimento di Protezione Civile - Consorzio RELUIS”, signed on 2013-12-27.

\section{References}

[1] Kasuga, A. (2011) Development of a New Bridge Construction Method Using Suspension Structures. Structural Concrete, 12, 65-75. http://dx.doi.org/10.1002/suco.201000002

[2] Stráský, J., Nečas, R. and Koláček, J. (2012) Dynamic Response of Concrete Footbridge. Structural Concrete, 13, 109118. http://dx.doi.org/10.1002/suco.201200001

[3] Durfee, R. (1986) Review of Triangular Cross Section Truss Systems. Journal of Structural Engineering, 112, 10881096. http://dx.doi.org/10.1061/(ASCE)0733-9445(1986)112:5(1088)

[4] Quaranta, G., Petrone, F., Marano, G.C., Trentadue, F. and Monti, G. (2010) Structural Design of Composite Concrete-Steel Beams with Spatial Truss Reinforcement Elements. Asian Journal of Civil Engineering, 12, 155-178.

[5] Mark, P. (2005) Truss Models for the Design of Reinforced Concrete Beams Subject to Biaxial Shear. Structures Congress 2005: Metropolis and Beyond, ASCE, New York, 1-10. http://ascelibrary.org/doi/abs/10.1061/40753(171)168

[6] Sanches Júnior, F. and Venturini, W.S. (2007) Damage Modelling of Reinforced Concrete Beams. Advances in Engineering Software, 38, 538-546. http://dx.doi.org/10.1016/j.advengsoft.2006.08.025

[7] Trentadue, F., Marano, G.C., Quaranta, G. and Mastromarino, E. (2011) Instability of Self-Supportingtruss-Reinforced Composite Steel-Concrete Beams. Waveng srl Ed., ISBN 978-88-903782-2-5, (in Italian).

[8] Trentadue, F., Quaranta, G., Marano, G.C. and Monti, G. (2011) Simplified Lateral-Torsional Buckling Analysis in Special Truss-Reinforced Composite Steel-Concrete Beams. Journal of Structural Engineering, 137, 1419-1427. http://dx.doi.org/10.1061/(ASCE)ST.1943-541X.0000390

[9] Petrone, F., Liotta, M., Monti, G., Marano, G.C. and Trentadue, F. (2011) Studio sperimentale per la valutazione del contributo del calcestruzzo nella resistenza a taglio delle travi reticolari miste. In: Braga, F. and Mezzina, M., Eds., Proceedings of the 14th Conference of the Italian National Association of Earthquake Engineering, Bari, September 2011.

[10] Monti, G. and Petrone, F. (2014) Shear Resisting Mechanisms and Design Capacity Equations for Composite Truss Beams (CTB). Journal of Structural Engineering, ASCE, (in press).

[11] Scotta, R. and Tesser, L. (2011) Prove sperimentali di rottura ciclica di nodi trave-pilastro realizzati con struttura reticolare mista. In: Braga, F. and Mezzina, M., Eds., Proceedings of the 14th Conference of the Italian National Association of Earthquake Engineering, Bari, September 2011.

[12] Nie, J., Fan, J. and Cai, C. (2004) Stiffness and Deflection of Steel-Concrete Composite Beams under Negative Bending. Journal of Structural Engineering, 130, 1842-1851. http://dx.doi.org/10.1061/(ASCE)0733-9445(2004)130:11(1842) 
[13] Castel, A., Vidal, T. and François, R. (2012) Finite-Element Modeling to Calculate the Overall Stiffness of Cracked Reinforced Concrete Beams. Journal of Structural Engineering, 138, 889-898.

http://dx.doi.org/10.1061/(ASCE)ST.1943-541X.0000520 
Scientific Research Publishing (SCIRP) is one of the largest Open Access journal publishers. It is currently publishing more than 200 open access, online, peer-reviewed journals covering a wide range of academic disciplines. SCIRP serves the worldwide academic communities and contributes to the progress and application of science with its publication.

Other selected journals from SCIRP are listed as below. Submit your manuscript to us via either submit@scirp.org or Online Submission Portal.
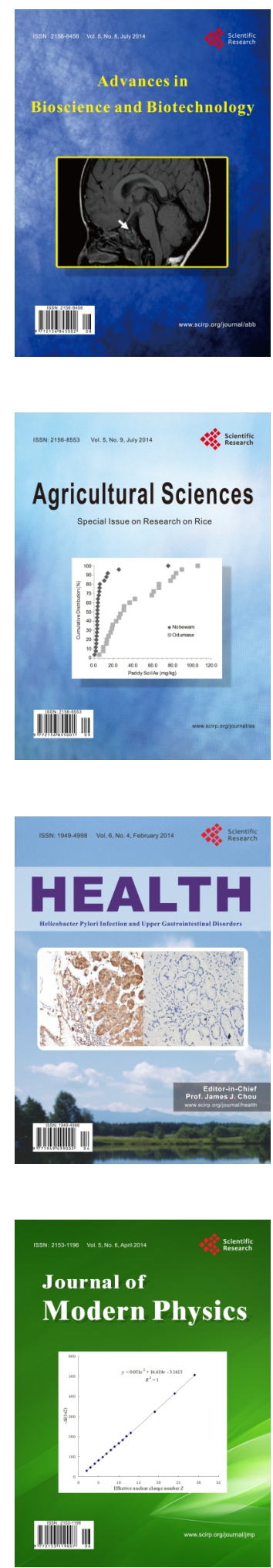
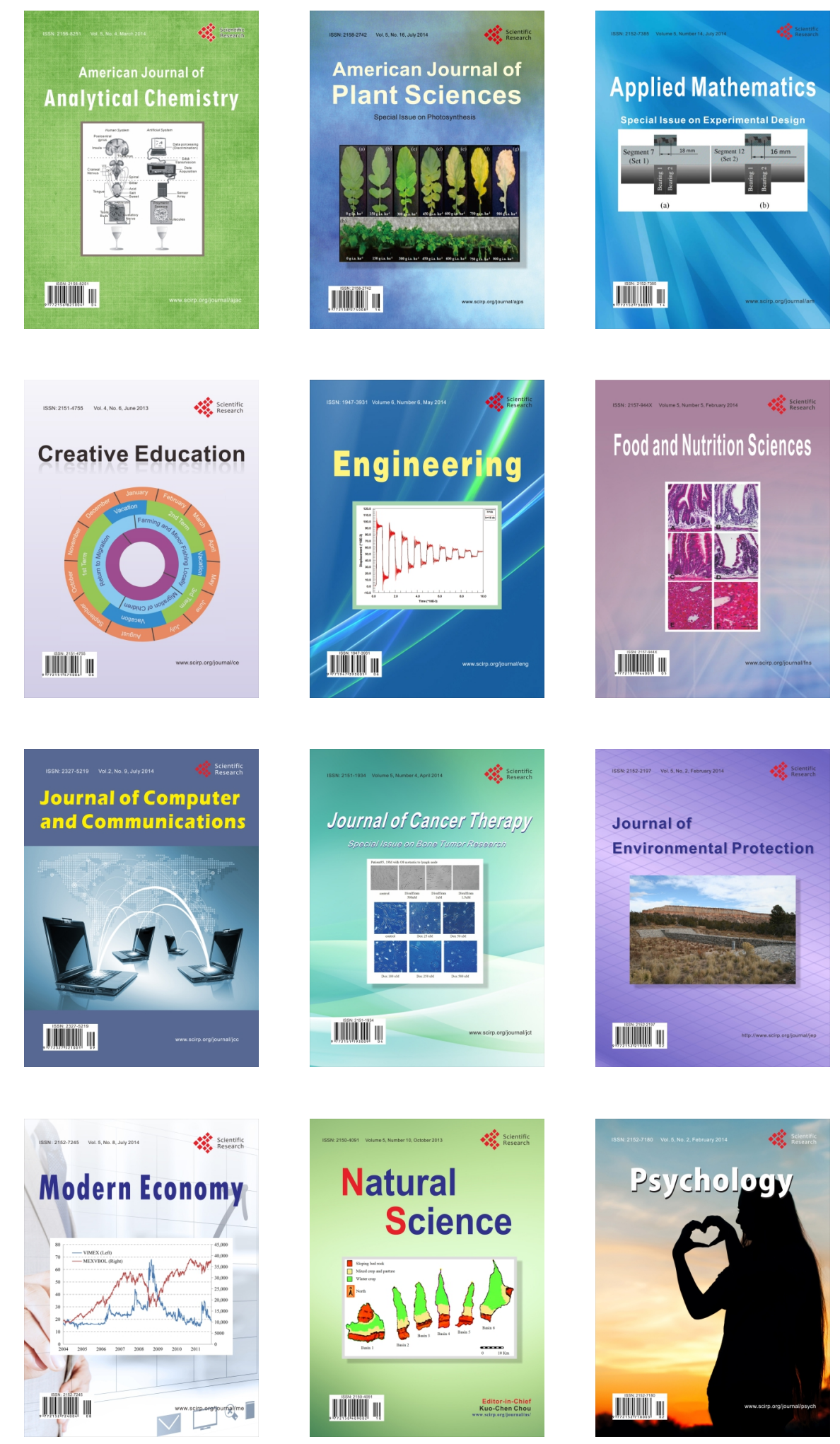